\title{
NECESIDAD E IMPOSIBILIDAD DEL NOSOTROS
}

\author{
TRABAJO DE GRADO \\ PRESENTADO COMO REQUISITO DE GRADUACIÓN PARA LA \\ MAESTRÍA EN FILOSOFÍA \\ Escuela de Ciencia Humanas \\ UNIVERSIDAD DEL ROSARIO \\ DIRECTOR: \\ ADOLFO CHAPARRO AMAYA
}

ANDRÉS DíAZ VELASCO

MAYO 2014 


\title{
NECESIDAD E IMPOSIBILIDAD DEL NOSOTROS
}

\author{
ANDRÉS DÍAZ VELASCO
}

Resumen: El presente ensayo explora un concepto de 'nosotros' que sin rechazar el uso gramatical de la enunciación se enfoca en la pragmática que le subyace, desde la cual las condiciones de colectividad y exclusividad del enunciado se confrontan con su alteridad ontológica fundamental. A la luz de la tesis sobre la antropología postestructural del etnólogo brasilero Eduardo Viveiros de Castro, se examinan, de un lado, la necesidad de enunciar al 'nosotros' en su calidad de radical diferenciador y, de otro, la imposibilidad de constituirlo sustancialmente en tanto remite inexorablemente a la otredad. En la primera parte, se expone que las teorías socioculturales no triviales de la antropología son realmente una coproducción entre el antropólogo y la comunidad estudiada. En segunda instancia, se presenta el modo por el cual el 'nosotros' da lugar a una diferencia irreductible no sólo previa al Mismo, sino esencial y afirmativa. En tercer lugar, se plantea una colectividad inmanente caracterizada por la multiplicidad que permanece por debajo de cualquier enunciación organizativa del 'nosotros' y compuesta por la alteridad maquínica. A modo de conclusión, el ensayo afirma al 'nosotros' en su devenir en cuanto un-otro-por-venir, el cual funciona como acto político existencial.

Palabras clave: nosotros, alteridad, diferencia, multinaturalismo, multiplicidad. 


\title{
NECESSITY AND IMPOSSIBILITY OF THE WE
}

\author{
ANDRÉS DÍAZ VELASCO
}

\begin{abstract}
This essay explores a concept of 'we' that without rejecting the grammatical use of enunciation focuses on pragmatic that underlies it, from which his community and exclusivity conditions confront with his fundamental ontological otherness. In light of poststructural anthropology thesis of the Brazilian ethnologist Eduardo Viveiros de Castro, discuss, on one hand, the necessity to enunciate the 'we' in his capacity of radical differentiator and, on the other, the inability to establish it substantially since refers inexorably to otherness. In the first part, it exposed that the nontrivial sociocultural theories of anthropology are a co-production between the anthropologist and the studied community. On second instance, it present the way in which the 'we' gives rise to an irreducible difference not only previous to the Self, but essential and affirmative. Third, it arise an immanent community characterized by an underlying multiplicity of any organizational enunciation of 'us' and composed by the machinic alterity. In conclusion, this paper affirms the 'we' in its becoming inasmuch as an-other-to-come, which functions as an existential political act.
\end{abstract}

Key words: we, otherness, difference, multinaturalism, multiplicity. 
Es conveniente conocer algo de las costumbres de diversos pueblos, para juzgar de las nuestras con criterio más sano y para no pensar que todo lo que se opone a nuestros usos sea ridículo y contra razón, como suelen hacer los que no han visto nada. Mas, cuando se emplea demasiado tiempo en viajar, acaba uno por ser extranjero en su propio país...

Descartes, Discurso del Método.

\section{Introducción}

Decir nosotros, implica al menos dos condiciones esenciales: por un lado, la colectividad o el grupo, yo con aquellos que están vinculados a mí; y, por otro, la exclusividad o separación de tal colectivo respecto de una colectividad distinta, los que no están vinculados a mí o ellos. La primera condición da cuenta del plural sociativo por el cual se pasa del yo como sí mismo al nos como los mismos. La segunda, muestra la diferencia de éstos en contraste con otros que vienen a ser los distintos. En consecuencia, el nosotros remite a la disociación de los unos y los otros, pudiéndose tratar no sólo de contraste sino de verdadero antagonismo ${ }^{1}$. Esto muestra el uso común del nosotros en las lenguas modernas, por lo cual el enunciante -que como sujeto de la enunciación, suponemos, sólo puede ser 'uno'- cuando dice nosotros realiza una acción doble: se vincula a una colectividad y se separa de otra. Se afirma a sí mismo en un ser/estar en común (bajo criterios que corrientemente se adjudican a la identificación, a la semejanza o a la pertenencia), mientras se niega en un ser/estar en diferencia (que se justifica normalmente como oposición y/o contradicción) ${ }^{2}$.

\footnotetext{
${ }^{1}$ Etimológicamente, nosotros proviene del latín vulgar nos alteri que implica un doble plural: por un lado, nos, el de ego o yo, y por otro, alter, el de otro, es decir, otros. De acuerdo con Gómez de Silva (2006: 485), nosotros "se usa para referirse al que habla y a otro u otros que comparten la acción del verbo". Según la gramática, en español antiguo se usaba simplemente la expresión nos, la cual funciona actualmente como acusativo ('nos vamos de aqui'), dativo ('el gobierno nos impone leyes injustas') y reflexivo ('nos declaramos inocentes'). Ahora bien, esta condición de doble plural, puede determinar sólo cuantitativamente su uso. No obstante, tomando la mera cantidad se esconden dos sentidos primordiales de la expresión: de una parte, la 'identificación' entre egos o, mejor, la absorción del yo en la colectividad (problema de la masa, la multitud, el pueblo, la gente, la comunidad); $y$, de otra, el contraste entre colectividades, propia del acusativo latín nos alteros, con el que se significaba algo como "ellos sí, pero nosotros no" (cf. Gómez de Silva, ibíd.).

${ }^{2}$ Evidentemente la segunda condición que implica el nosotros la comparte con el yo: la enunciación por medio de la cual el yo se afirma a sí mismo sólo en la medida en que excluye el ser-otro; por ello, participa de los mismos problemas. Sin embargo, la condición de colectividad del nosotros pone en jaque la autoafirmación del yo en el sentido de la necesaria vinculación por la que éste se dice a sí mismo en relación
} 
Sin embargo, más allá de la gramaticalidad de la enunciación - por la que puede asumirse llana e invariablemente este doble sentido del nosotros-, la exclusión de una colectividad por otra, al explicitar alguna clase de diferencia (racial, religiosa, generacional...), no siempre resulta efectiva en términos pragmáticos (Deleuze y Guatarri, 1997: 81 y ss.). En la inmanente relación entre cuerpos (no solamente parlantes) pueden presentarse casos en que el nosotros se difumina o en los que resulta supremamente difícil delimitar su 'sustancia', perdiendo de forma contundente las condiciones que lo hacen gramaticalmente definible. Como la experiencia nos muestra, la enunciación del nosotros no requiere sólidas condiciones estructurantes, como la constitución de un partido político, de una agrupación étnica, de género o de animalistas. Así como hay nosotros en que los 'componentes' no tienen presencia corporal (familiares muertos), y nosotros que se establecen por casualidad (los estudiantes de un curso), hay nosotros que se difuminan tan rápido como se constituyen (el de quienes esperan un bus, por ejemplo). En general, de los nosotros que se pueden enunciar en la cotidianidad, no todos están comprometidos con una sociología de segmentariedad dura o molar ${ }^{3}$.

con otros: habla de sí pero no lo hace en nombre propio. En otras palabras, el 'nosotros' sirve de principio para la multiplicidad del 'yo' (problema que exploraremos más adelante).

${ }^{3}$ Esta no es simplemente una condición circunstancial de la enunciación, puede ser histórica. Siguiendo el planteamiento de Mauricio Lazzarato (2007) a propósito de los actuales movimientos sociales en Francia, podemos señalar dos maneras distintas de conformarlos y concebirlos según nos refiramos a las sociedades a las que pertenecen, de acuerdo con el esquema foucaultiano de las sociedades disciplinarias y las sociedades de seguridad (o de control, según la expresión de Deleuze). Lazzarato describe un movimiento político de personas que trabajan en las industrias culturales de Francia denominados 'los intermitentes', y afirma que su organización es claramente una multiplicidad ya que no siguen un solo patrón de actuación, no siguen a un único líder, no militan de forma permanente en partidos políticos, ni se asocian como gremio en sindicatos (por el contrario, rechazan que los sindicatos tradicionales intenten apropiárselos). De este modo, han roto las formas de organización y lucha de los colectivos, diferenciados en la tradición marxiana en 'clases sociales', de las sociedades de encierro. En este nuevo escenario, las colectividades no siguen una sola manera de conformación como lo pensaba, por ejemplo, Hugo Zemelman, quien insistió en la organización de colectividades capaces no sólo de ser conscientes de sí mismas, tanto histórica como culturalmente, sino, conforme a esta consciencia, de organizarse y conformar un proyecto político alrededor de un interés colectivo de beneficio general. Esta perspectiva afirma que a pesar de que no siempre los interés colectivos delineen una fuerte voluntad colectiva, es ésta el motor de verdaderas agrupaciones de individuos con algo en común (una condición económica, un líder o una identidad cultural) cohesionados por un fin de largo alcance (Zemelman, 2006, 2011). En el caso que indica Lazzarato, las personas no se cohesionan específicamente por un líder ni por una identidad, tampoco responden a un interés común, ya que las condiciones económicas no son iguales o no se comparten. Hay una diferencia esencial que los coloca en una situación de incomposibilidad. En este sentido, la colectividad molar, más que ingenua o ilusoria, pertenece a un tipo específico de sociedad, resultando inaplicable y/o políticamente fútil en otra. 
Un ejemplo importante de esta disolución o falta de sustancialidad del nosotros, se presenta implícitamente en el libro Metafísicas Caníbales (2010) del etnólogo brasilero Eduardo Viveiros de Castro. Su investigación, aunque de forma no intencional, muestra la imposibilidad de consolidar un nosotros no obstante la necesidad constante de recurrir a él. El punto es que, aunque el nosotros depende de la irreductibilidad de la diferencia, no hay modo de constituirle sólidamente como unidad. $\mathrm{Si}$ bien Viveiros requiere metodológicamente de la colectividad y de la exclusividad que le brinda el nosotros (conforme la dicotomía naturaleza-cultura), no puede escapar a la imposibilidad de su sustancialidad: los mismos remiten irremediablemente a los otros. En sus palabras, "no hay lugar para un 'nosotros' sino ya determinado por la alteridad" (Viveiros, 2010: 239). De esta manera, en lo que viene presentamos modos en que se disuelve el nosotros, diagramados a partir del trabajo de Viveiros de Castro, con los cuales se da paso a una colectividad pre-cultural y maquínica.

En la primera parte, se expone el modo como la aparente pureza de la teoría antropológica de occidente da paso a un inevitable -y recíproco- contagio intelectual. Se trata de la disolución de una forma del nosotros propiamente disciplinar correspondiente al enfoque epistemológico y metodológico de la antropología postestructural que, ante el encuentro con el pensamiento y la forma de vivir del Otro (el amerindio), lleva a cabo una experimentación con lo propio (involucrando en el 'nosotros' al distinto). En segunda instancia, se presenta el modo por el cual el nosotros pierde al mismo tiempo la tendencia a asociar (por ejemplo, cuerpos geográficamente situados, o costumbres históricamente afines) y a constituir una radical distinción con un Otro del que se distancia, para dar lugar a una diferencia irreductible no sólo previa (respecto a la sustancialidad del 'yo' y del 'nosotros') sino esencial y afirmativa. Se muestra así un nosotros radicalmente diferencial, cuya alteridad no está basada en lo idéntico, ni derivada de un Mismo común.

En esta línea de ideas, en tercer lugar, se plantea una colectividad desplegada en alteridad maquínica, en flujo deseante, como unidad anárquica compuesta por unos otros singulares. Aquí la disolución conlleva a una colectividad inmanente caracterizada por la multiplicidad 
subyacente a cualquier enunciación organizativa de 'nosotros', con lo cual se asegura su insustancialidad. Se trata de una colectividad abierta o atravesada por una alteridad ontológica, imposible de circunscribir en el Mismo. Finalmente, a modo de conclusión, el ensayo resalta un nosotros en devenir o, lo que es lo mismo, la constante disolución del nosotros en cuanto un-otro-por-venir.

\section{A. Disciplina híbrida: la disolución del nosotros epistemológico}

La primera anotación que haremos sobre la alteración del nosotros desde Viveiros de Castro, responde a un objetivo claramente planteado por él en relación con el proceso de reconstitución de su disciplina, en el que propone "reconsiderar bajo una nueva luz algunas cuestiones clásicas de la etnología regional" (2003: 225). Viveiros contrapone dos versiones de la antropología como dos prácticas disciplinares distintas. La primera es una antropología exotista y primitivista, "un teatro perverso en el que el 'otro' siempre es 'representado' o 'inventado' de acuerdo con el sórdido interés de Occidente” (2010: 15). La segunda responde, por el contrario, a la necesidad de reconstitución de la disciplina de acuerdo con la tesis de que "todas las teorías antropológicas no triviales son versiones de las prácticas de conocimiento indígena" (ibíd. 17) ${ }^{4}$.

La antropología postestructural, en este sentido, cumpliría una función renovadora de las interpretaciones que circulan respecto de los otros en el discurso etnológico (es decir, los no-occidentales); pero, más fundamental aun, asumiría de forma honesta y radical el hecho de que la teoría etnológica misma no es una construcción exclusivamente occidental. Según Viveiros, "[e]s preciso extraer todas las consecuencias de la idea de que las sociedades y las culturas que constituyen el objeto de la investigación antropológica influyen, o para decirlo claramente coproducen, las teorías sobre la sociedad y la cultura formuladas a partir de esas

\footnotetext{
${ }^{4}$ De acuerdo con Viveiros, para la primera antropología, la mismidad del nosotros se sobrepone a cualquier Otro, éste funciona como referente para describir lo que se 'es' en tanto el otro 'no lo es'; y, por eso, “a fuerza de ver siempre al Mismo en el Otro - de decir que bajo la máscara del otro es 'nosotros' lo que nosotros mismos contemplamos-, terminamos por contentarnos con acortar el trayecto que nos conduce directamente al final y no interesarnos más que en lo que 'nos interesa', a saber, nosotros mismos" (2010: 15). Se trata, pues, de una antropología colonialista sujeta a la convencional metafísica occidental en tanto ésta "es verdaderamente la fons et origo de todos los colonialismos" (ibíd. 20).
} 
investigaciones" (2010: 15, cursivas mías). Esta cuestión resulta importante para el problema del nosotros, en el sentido en que propone una suerte de hibridación epistemológica a través del intercambio 'intelectual' por el que las nociones de los antropólogos, propias de su formación académica dentro del alma occidental, al estar empapadas de la pragmática intelectual del colectivo estudiado, se 'contaminan', conformándose un 'nosotros' epistemológico en el que el antropólogo no habla 'por' ni 'de' de los otros, sino ‘con' ellos.

De este modo, la antropología, en tanto que disciplina académica, o incluso como quehacer profesional, adquiere una nueva misión, a saber, "la de ser la teoría-práctica de la descolonización permanente del pensamiento" (Viveiros, 2010: 14). Se abandona, entonces, el propósito de describir las costumbres ajenas desde las propias, es decir, desde lo que el sujeto del discurso antropológico no es, y la antropología se convierte en una práctica abiertamente política (Viveiros, 2010: 24). Ahora bien, tal renovación se produce de tres maneras distintas: (i) por la creación o producción conceptual propiamente antropológica; (ii) por la reordenación de las prácticas investigativas; y (iii) por el ejercicio de reasumir problemas y temas no sólo emblemáticos sino de necesaria reformulación.

(i) Viveiros concibe que parte del trabajo que ha de adoptar la antropología postestructural consiste en la "elaboración de un concepto antropológico de concepto" (2010: 18). El discurso antropológico, de acuerdo con ello, no puede negar que siempre ha adherido a sí el producto de la imaginación del estudiado, esto es, el mundo tal cual lo ve y lo vive la comunidad en cuestión: se trata pues de "la antropología que tiene a ese pueblo como agente y no como paciente teórico" (Viveiros, 2010: 70).

La creación conceptual antropológica descansa, entonces, en el acto de pensar desde un Afuera. Y los conceptos antropológicos, por tanto, son deudores de los pueblos que se estudian, surgen de un co-constructivismo; pero no simplemente porque emerjan en la práctica investigativa de campo del antropólogo profesional (exo-antropología), sino porque su ejercicio es propiamente una comparación, o sea, el "procedimiento implicado en la traducción de conceptos prácticos y discursivos del 'observado' en los términos del 
dispositivo conceptual del 'observador"” (Viveiros, 2010: 71). Se acepta así, que la antropología construye conceptos a partir del intercambio con las sociedades y culturas estudiadas y, por tanto, “[1]o que esos conceptos reflejan es cierta relación de inteligibilidad entre las dos culturas, y lo que proyectan son las dos culturas en cuanto sus propias presuposiciones" (Viveiros, 2010: 202).

Esta producción de conceptos le da a la antropología un carácter especial de creación bajo dos condiciones: primero, la consideración de que el colectivo estudiado es tan productor de sentido como lo es la sociedad occidental y, segundo, el tomar en serio tal sentido, es decir, connotarlo como 'concepto' y no como creencia obsoleta, imaginario impreciso o idea absurda. En palabras de Viveiros:

Ni una forma de doxa, ni una figura de la lógica (ni opinión ni proposición), el pensamiento indígena debe ser tomado -si se quiere tomarlo seriamente-como una práctica del sentido: como dispositivo autorreferencial de producción de conceptos, de "símbolos que se representan a sí mismos". [...] $\mathrm{Ni}$ representaciones, individuales o colectivas, racionales o por lo menos razonables, que expresarían parcialmente estados de cosas anteriores y exteriores a ellas mismas; ni categorías o procesos cognitivos, universales o particulares, innatos o adquiridos, que manifestarían propiedades de una cosa del mundo, ya sea el espíritu o la sociedad: el objeto cuya existencia se afirma aquí es el de los conceptos indígenas, el de los mundos que constituyen (mundos que así lo expresan), el fondo virtual del que han surgido (2010: 210, 201. Cursivas mías).

De esta manera, lo que emerge en la lectura de Viveiros es un proceso de dislocación del nosotros epistemológico que supuestamente se reconstruía o reafirmaba cada vez que se hacía un ejercicio de 'odiosa comparación' o una 'traducción interpretativa' de las comunidades no occidentales exhibiendo, precisamente, lo que no tienen de Occidente. La creación o coproducción de conceptos propiamente antropológicos, dirá, se produce al asumir la “extraproposicionalidad de todo pensamiento creador ('salvaje') en su positividad integral” (Viveiros, 2010: 63). Se trata de un 'nosotros' sin autor, sin voz unipersonal. 
(ii) El segundo modo de renovación disciplinar se basa en la redistribución de las tareas o la reordenación de las prácticas investigativas de la antropología. Como hemos señalado, la antropología postestructural ha de responder ahora al ideal de ser un ejercicio de descolonización del pensamiento, lo que significa básicamente que ha de asumir la tarea epistemológico-política de posibilitar otro modo de pensar. Se trata de experimentar con el propio pensamiento por medio de la experiencia con otros pensamientos: el amerindio, de un lado, y el filosófico, de otro ${ }^{5}$.

Tal experimentación se realiza conforme dos procedimientos complementarios que definen la nueva práctica de la antropología postestructural: primero, como hemos mostrado ya, la antropología deja de contentarse con describir minuciosamente el punto de vista del indígena, y antes bien lo adopta en una producción conceptual conforme un procedimiento de mutua interpelación. En segundo lugar, la antropología se conecta con la filosofía, obteniéndose una: "síntesis disyuntiva entre la antropología, entendida como metafísica experimental o geofilosofía de campo, y la filosofía, entendida como la práctica etnoantropológica sui generis que consiste en crear conceptos" (Viveiros, 2010: 79). En este sentido, la antropología en tanto que postestructuralista transforma sus prácticas investigativas reordenándolas en torno a la producción de conceptos antropológicos y a la lectura filosófica a la luz del pensamiento salvaje; es decir, las prácticas se renuevan de acuerdo al establecimiento de esa alianza demoníaca, como dice Viveiros, por la que se da "la entrada a un estado (una meseta de intensidad) de descolonización permanente del pensamiento" (Viveiros, 2010: 79).

Ahora bien, la antropología no se puede conectar con 'cualquier' filosofía; esta redefinición de las prácticas investigativas responde, a su vez, a una filosofía renovadora, a una filosofía que pretende, precisamente, una nueva imagen del pensamiento. Así, la antropología posestructuralista es producto del matrimonio contra natura de Levi-Strauss con Deleuze

\footnotetext{
${ }^{5}$ Según Viveiros, el objeto de la antropología postestructural "no es tanto el modo de pensamiento indígena como los objetos de ese pensamiento, el mundo posible que sus conceptos proyectan. [...] No se trata [...] de proponer una interpretación del pensamiento amerindio, sino de llevar a cabo una experimentación con éste, y por consiguiente con el nuestro: "Every understanding of another cultur is an experiment with one's own" [Toda comprensión de otra cultura es un experimento con la propia] (Wagner)" (Viveiros, 2010: 200).
} 
(de quien se adopta sustantivamente el concepto de multiplicidad ${ }^{6}$ ). Reordenado el quehacer antropológico, entonces, el Otro que era, por un lado, sujeto de estudio y, por otro, un metafísico occidental convencional, conviene en una relación diferencial de entrecruzamiento, o en palabras de Viveiros, de "circulación infinita de perspectivas" con el 'nosotros' de la antropología, volviéndolo un otro del Mismo que pensaba ser. Y se entiende que sea una tarea epistémico-política, eminentemente, porque este 'nosotros' debe funcionar como transformador del mundo.

(iii) En último lugar, en el proceso de reconstrucción de la antropología, la afirmación de un nosotros antropológico que es Otro se da al reasumir con carácter alterador los patrones de interpretación clásicos de la antropología estructural. Evidentemente, esto se sigue de los dos procesos mencionados anteriormente, pero no como consecuencia sino como parte constitutiva de la antropología postestructural que debe rehacer los esquemas interpretativos elaborados en torno del pensamiento amerindio -visto generalmente como una forma primitiva del pensar europeo o bien como una ficción mitológica.

Este procedimiento en particular, ocupa gran parte del libro de Viveiros, y quizás sea la parte más 'revolucionaria' del mismo. Por un lado, porque renueva la relación de varias de las diadas más renombradas en la antropología, lo que conlleva la gestación de conceptos como multinaturalismo, perspectivismo, enemiguismo, intercambio-robo y alianza contra natura (o alianza intensiva) ${ }^{7}$. Por otro, porque sugiere la apropiación de la ontología amerindia respecto a lo que implican los puntos de vista o el perspectivismo propiamente dicho: ya no se trata de seguir el esquema de la representación verdadera ${ }^{8}$, ni de sostener la

\footnotetext{
${ }^{6}$ Según Viveiros: "[l]a multiplicidad deleuziana es el concepto que parece describir mejor no sólo las nuevas prácticas de conocimiento propias de la antropología, sino también los fenómenos de las que éstas se ocupan" (2010: 100). Con esto, Viveiros dirá que el filósofo es un pensador salvaje (cf. 2010: 112), y la alianza se definirá del siguiente modo: "Una nueva imagen del pensamiento. Nomadología. Multinaturalismo" (Viveiros, 2010: 97).

7 Entre las díadas hay que nombrar: 'hombre/animal', 'individuo/sociedad', 'primitivo/civilizado', 'naturaleza/cultura', 'filiación/alianza', 'mito/historia', 'totemismo/sacrificio' y 'chaman guerrero/chaman sacerdote', renovadas por las nociones deleuzianas de multiplicidad, devenir y diferencia.

8 "Una perspectiva no es una representación porque las representaciones son propiedades del espíritu", y la perspectiva es eminentemente corporal (Viveiros, 2003: 218).
} 
existencia de un único mundo real (como cosa-en-si o hecho bruto) representable ${ }^{9}$; sino de la configuración de mundos de acuerdo con un mismo modo de ver. En el multinaturalismo perspectivista, dice Viveiros

todos los seres ven ('representan') el mundo de la misma manera: lo que cambia es el mundo que ven. [...] las cosas que ellos ven [los sujetos no-humanos], cuando las ven como nosotros [los humanos] las vemos, son otras: lo que para nosotros es sangre, para los jaguares es cerveza; lo que para las almas de los muertos es un cadáver podrido, para nosotros es mandioca fermentada; lo que nosotros vemos como un charco de barro, para los tapires es una gran casa ceremonial... [...] diferentes tipos de seres ven cosas diferentes de la misma manera (2010: 53-54) ${ }^{10}$.

Con esto, Viveiros muestra en qué sentido los patrones de la antropología se renuevan, considerando en el fondo que la comparación, como instrumento analítico, no es otra cosa que la transformación del 'mundo' del observado en conceptos por parte del observador, por lo que sirve exclusivamente a la traducción, la cual es la deformación o subversión del 'dispositivo conceptual' del observador por el intento de expresar el mundo del observado. En este sentido, con Viveiros, la antropología no explica, ni interpreta, ni contextualiza al Otro, ella compara para traducir, de forma tal que el Otro del otro (del amerindio) deviene un otro respecto del que era o pensaba ser. Afirma entonces:

\footnotetext{
9 “El problema del perspectivismo amerindio, pues, no es encontrar la referencia común (por ejemplo, el planeta Venus) a dos representaciones diferentes (la 'Estrella de la mañana' y la 'Estrella de la tarde'), sino por el contrario, el de contonear el equívoco que consistiría en imaginar que cuando el jaguar dice 'cerveza de mandioca' está haciendo referencia a la 'misma cosa' que nosotros, simplemente porque 'quiere decir' la misma cosa que nosotros" (Viveiros, 2010: 57).

${ }^{10}$ Que todos los seres no-humanos vean el mundo como nosotros los humanos lo vemos significa, entre otras cosas, que ellos se ven a sí mismos como nos vemos a nosotros, es decir, como 'personas': objetos intencionales constituidos por relaciones sociales (Cf. Viveiros, 2010: 35 y ss.). "Si los humanos se ven como humanos y son vistos como no-humanos -animales o espíritus- por los no-humanos, entonces necesariamente los animales deben verse como humanos" (id.: 51). Esto asegura que las 'cosas' que ellos ven no sean las mismas que vemos nosotros, lo que lleva a Viveiros a plantear la constitución de multiplicidades pre-individuales, intensivas y rizomáticas como la 'sangre/cerveza'. Es decir, si aquello que nosotros vemos como sangre, el jaguar lo ve como cerveza, no es ni sangre ni cerveza sino ambas cosas a la vez, y muchas otras dependiendo del 'punto de vista'. De este modo, si el jaguar, por ejemplo, no está viendo la misma cosa que nosotros, no está 'queriendo decir' lo mismo: dice otra cosa accesible sólo a través del diálogo transespecífico que realiza el chamán como devenir entre puntos de vista (cf. Viveiros, 2003: 200 y ss.). De este modo, el 'nosotros' correspondiente a los 'humanos', expresa sólo un punto de vista compartido, lo que significa, en una palabra, que lo común entre humanos es su perspectiva y de ninguna manera alguna clase de 'esencia', tal como se verá más adelante.
} 
Si hay algo que corresponde de derecho a la antropología no es la tarea de explicar el mundo de los otros, sino la de multiplicar nuestro mundo, "poblándolo con todos esos expresados que no existen fuera de sus expresiones". Porque nosotros no podemos pensar como los indios; como máximo podemos pensar con ellos (Viveiros, 2010: 211).

Así las cosas, esta renovación disciplinar resulta singularmente importante ya que demarca un límite con el Otro en tanto que no hay un mismo mundo por 'compartir' con él, sino un punto de vista por devenir, lo cual constituye la posibilidad de gestar otros mundos. Se trata, parafraseando a Deleuze, del Otro como expresión de un mundo posible $\mathrm{y}$, parafraseando a Levi-Strauss, de que dos es siempre más que dos. En el estar 'ante' el Otro, como dicen Deleuze y Guattari (2005), algo de uno pasa al otro. La cuestión está en la potencia de la mutua captura, en la común desterritorialización de lo propio: "el pensador [...] deviene indio, no acaba de devenirlo, tal vez 'para que' el indio que es indio devenga él mismo algo más y se libere de su agonía” (Deleuze y Guattari, 2005: 111).

En consecuencia, la antropología ha de ser considerada como un "discurso conceptualmente determinado por los discursos sobre los cuales discurre" (Viveiros, 2010: 213); lo que muestra al necesario nosotros epistemológico siendo atravesado inapelablemente por la alteridad. Los nuevos procedimientos afirman un nosotros como Otro porque insisten en el papel de la antropología de experimentar consigo 'por medio' de otros; y la experimentación con el propio pensamiento resulta, en este sentido, no sólo pensar desde fuera sino pensar-se desde afuera: "pensar desde un afuera para ir al encuentro del pensamiento del Afuera, por la otra punta" (Viveiros, 2010: 81). La hibridación epistemológica, entonces, da cuenta de un nosotros en constante modificación, un nosotros que es siempre otro. $\mathrm{O}$, en pocas palabras, un nosotros imposible porque no llega nunca a constituirse como tal sin, a la vez, cambiar.

Se aprecia, con ello, una suerte de trasfondo ontológico en que el nosotros (al igual que el yo) no puede tratarse como dado de antemano. El devenir, concepto fundamental para la renovación de la antropología según Viveiros, descansa sobre la existencia previa de dos 
términos, es cierto; pero tales términos no 'son' ellos mismos, en sentido primordial ${ }^{11}$. Por esta razón, no se trata de mera transdisciplinariedad ni de interculturalidad práctica, la relación de la antropología con la filosofía y del antropólogo con el amerindio se libra en un campo en que la alteridad subyace como condición de posibilidad de 'ser' (una cosa u otra) y de devenir. La necesidad del nosotros (tal como la del yo), a la larga, garantiza y sostiene su existencia, su ser en cuanto tal; pero la inminencia de un Otro -por la que el devenir tiene sentido- impone su imposibilidad. Es preciso, entonces, indicar en qué consiste ese campo ontológico de la alteridad en relación con el nosotros.

\section{B. Nosotros y ellos: la diferencia irreductible}

La necesidad de acudir al nosotros, en Viveiros de Castro, responde al contraste que se debe establecer entre lo occidental y lo amerindio, por un lado, y lo humano y lo animal, por otro, conforme la ventaja metodológica que brinda mantener (en principio) la dicotomía naturaleza-cultura. A partir de ésta, Viveiros diferencia un nosotros para dar cuenta de un ellos, y mantener su 'distancia', incluso, a extremos opuestos. Enfrenta, así, el multinaturalismo amerindio al multiculturalismo occidental como "dos modos muy distintos de conjugación de lo múltiple" (2010: 57). Sin embargo, tal oposición no descansa en una mera crítica al multiculturalismo en favor del multinaturalismo, sino en la diferenciación de los fundamentos que les sirven de base, de modo que se puede concebir su simultaneidad no obstante su confrontación respecto de la animalidad, de la corporalidad y de la noción de Humanidad -sobre la cual se suele enunciar en Occidente una suerte de 'nosotros' universal. Reconocer los alcances de cada polo, sobre todo en relación con las luchas sociales dentro de la tradición occidental, resulta entonces pertinente, trazando su respectiva localización dentro de una multiplicidad pre-cultural.

\footnotetext{
${ }^{11}$ Con base en Deleuze y Guattari, Viveiros de Castro considera que "el devenir es una relación real, molecular e intensiva, que opera en un registro otro que el de la relacionalidad todavía demasiado morfológica del estructuralismo. [...] Ni metáfora ni metamorfosis, un devenir es un movimiento que desterritorializa los dos términos de la relación que crea, extrayéndolos de las relaciones que los definían para asociarlos a través de una nueva 'conexión parcial'” (Viveiros, 2010: 166-167). En diálogo con Parnet, Deleuze afirma que "los devenires no son fenómenos de imitación ni de asimilación, [sino] fenómenos de doble captura, de evolución no paralela, de bodas entre dos reinos" (2004: 6).
} 
El multiculturalismo o relativismo cultural, en tanto que teoría en defensa de los pueblos de tradición no occidental -en autores como Lévi-Strauss y Peter Winch (1994), por ejemplosalvaguarda la diversidad de culturas y relativiza el papel central de la civilización occidental, ampliando el número de civilizaciones y desbaratando la idea de progreso lineal en el que unas sociedades representarían los estadios más infantiles de otras, ubicándose Occidente como culmen (fin de la historia según Fukuyama) y patrón de civilización. El multiculturalismo aparece, en cuanto a la política se refiere, como exigencia de reconocimiento de las minorías tanto como de la diversidad misma; o sea, no sólo como aceptación de las diferencias culturales (como el uso del hiyab islámico o la ablación emberá), sino como cortesía necesaria o vital que se le debe a cierta identidad de lo humano. De acuerdo con el planteamiento de Taylor, se trata de una política de la diferencia ensamblada con la dignidad igualitaria, sostenida por la asignación de 'igual valor' que presuponen las culturas, en tanto

es razonable suponer que las culturas que han aportado un horizonte de significado para gran cantidad de seres humanos, de diversos caracteres y temperamentos, durante un largo periodo [...] casi ciertamente deben tener algo que merece nuestra admiración y nuestro respeto, aún si éste se acompaña de lo mucho que debemos aborrecer y rechazar (Taylor, 1993: 106).

El multiculturalismo ha servido a las luchas de las minorías tanto para el fortalecimiento y reconocimiento de su 'identidad' respecto de la cultura mayoritaria, como para la defensa legal de sus derechos vitales en conjunto con la supervivencia de sus culturas: luchas contra la homogenización y la imposición hegemónica de la cultura occidental (Narváez, 2005; Grosso, 2006; Villa y Grueso, 2008). De este modo, la inquietud multicultural radica, si sintetizamos abusivamente, en la igualdad que se debe asignar a las culturas para identificarlas -y para que se identifiquen a sí mismas- por medio de su diferenciación con otras, aunque así sus diferencias queden atrapadas en los esquemas (normalmente jurídicos y políticos) de tal igualdad ${ }^{12}$.

\footnotetext{
${ }^{12}$ Es imposible reducir las aristas del planteamiento político, tanto como del jurídico y del filosófico, sobre el multiculturalismo, teniendo en cuenta además sus distintas versiones y sus debates y logros políticos. Hay que reconocer, por ejemplo, que en el pensamiento de Taylor no se acepta finalmente ninguna 'neutralidad cultural'; y que, en términos normativos tanto como éticos, el multiculturalismo de Estado tiende a un
} 
Pero si el punto está en no homogenizar las diferencias tras la exigencia de igualdad, se demanda una forma de liberalismo, como dice Taylor recurriendo a Hegel, que consista en un "régimen del reconocimiento recíproco entre iguales [...] en una sociedad informada con un propósito común, en que «el ‘yo' es ‘nosotros' y 'nosotros' el ‘yo'»” (1993: 76-77). Siguiendo a Hegel, sólo en el movimiento del actuar real se puede presentar una armonía tal entre el nosotros y el yo, de forma que la tautología de la expresión "el yo es nosotros y nosotros el yo", se valida únicamente por el sentido pragmático de lo que es común. Sin embargo, el modo de realización de la conversión entre el plural y el singular de la primera persona no es - o no ha sido hasta ahora- uno solo: por un lado, esta suerte de absorción del yo por parte de la colectividad va desde la comunitariedad hasta la masificación mercantil; por otro, el gobierno (bajo el mismo esquema hegeliano) funciona como una facción que presume el entendimiento de la voluntad general contrapuesto a las voluntades individuales, lo que supone siempre más una idealización del 'nosotros' que una práctica colectiva realmente armoniosa. En este sentido, la universalidad de la formula hegeliana resulta insostenible en cuanto a las practicidades de los colectivos y de los individuos ${ }^{13}$.

El problema, entonces, no radica únicamente en ser iguales ante la ley, o en que la ley medie entre las diferencias en función de las acciones reales de los individuos corporal y/o culturalmente diferenciables; el problema consiste en la base conceptual desde la que se

efecto totalizador en que se impone una sola forma de vivir con base en las implicaciones de la 'comunidad global' y los 'derechos humanos'. Y, asimismo, como muestra Taylor, hay posibilidad de insertar en el debate otras modalidades de liberalismo que sopesan "la importancia de ciertas formas de trato uniforme con la importancia de la supervivencia cultural, y optan a veces en favor de ésta última" (1993: 91). Reconocer a las minorías y además admitir el funcionamiento de un Estado-nación heterogéneo, como muestra Kymlicka (2009), es entonces un reto que confronta las mismas lógicas de la democracia liberal en la cual se chocan posiciones tan disímiles sobre la igualdad y la libertad que, a pesar del optimismo por ciertos logros políticos en algunos países, debe admitirse un inevitable retroceso de la diversidad en cuanto a la difusión global del multiculturalismo -estando siempre el terrorismo, por supuesto, como límite de la tolerancia y de la justicia (Bartra, 2013). La negociación de venta de tierra entre amerindios y europeos, que desde la Conquista es un problema derivado de la visión y del trato hacia la naturaleza, así como el desplazamiento forzado de comunidades indígenas enteras por medio de la violencia armada, son casos que suponen una fácil superación por medio de la declaración de derechos de pueblos indígenas, los cuales obedecen a las mismas lógicas de universalización de los derechos humanos defendidos por la ONU; sin embargo, resultan más bien conflictos irresolutos que superan la exigencia de derechos y remiten al demérito de esos grupos culturales. En este sentido, ya en el mundo académico se ha planteado con vehemencia, en qué sentido el multiculturalismo es un discurso acorde con el imperialismo de corte liberal.

${ }^{13}$ Sobre Hegel, ver Fenomenología del espiritu, sección VI "El Espíritu". 
hace la ley, es decir, en las nociones que sirven como sustento y justificación de las reglas de acción que afectan a las colectividades y a los individuos. Y, por ello, la concepción o pragmática intelectual amerindia, denominada por Viveiros perspectivismo multinaturalista, resulta radicalmente distinta a la occidental. Según dice las cosmologías "multiculturalistas" modernas [...] se apoyan en la implicación mutua entre la unicidad de la naturaleza y la multiplicidad de las culturas -la primera garantizada por la universalidad objetiva de los cuerpos y de la sustancia, la segunda generada por la particularidad subjetiva de los espíritus y significados-, [mientras que] la concepción amerindia supondría, por el contrario, una unidad del espíritu y una diversidad de los cuerpos. La "cultura" o el sujeto, representaría la forma de lo universal, y la "naturaleza" o el objeto la forma de lo particular (Viveiros, 2010: 34).

En este sentido, asevera Viveiros en contraste con algunos estudios antropológicos, el multinaturalismo perspectivista trata de 'algo' irreductible en sus premisas y conclusiones “a nuestro concepto corriente de relativismo" (2003: 192). Éste consiste en una concepción “común a muchos pueblos del continente, según la cual el mundo está habitado por diferentes especies de sujetos o personas, humanas y no humanas, que lo aprehenden desde puntos de vista distintos" (Viveiros, 2003: 192). Tales puntos de vista son los de múltiples subjetividades que pueblan el universo, no sólo humanos y animales sino además “dioses, espíritus, muertos, habitantes de otros niveles cósmicos, plantas, fenómenos meteorológicos, accidentes geográficos, objetos e instrumentos" (id.193). Las perspectivas son subjetivas no porque estén definidas por un 'sujeto dado', sino (siguiendo al Leibniz de Deleuze) porque es sujeto quien ocupa o accede a un punto de vista. Concibe Viveiros que "ahí donde estuviere el punto de vista, estará también la posición de sujeto [por lo que] el perspectivismo amerindio procede según el principio de que el punto de vista crea el sujeto; será sujeto quien se encuentre activado o accionado por el punto de vista" (2003: 212).

De esta manera, en tanto esta aprehensión del mundo refiere a un asunto pragmático y no meramente reflexivo, el mundo viene a ser más bien uno particular en cuanto cada punto de vista habita o territorializa el suyo propio (el mundo que cada cuerpo ve). No se puede 
afirmar, entonces, que se trate de la misma selva o de la misma ciudad, así como tampoco de la misma sangre ni de la misma bebida ${ }^{14}$. Lo que se explica, además, por el hecho de que, para los amerindios, el cuerpo es el gran diferenciador, es decir "aquello que sólo une a seres del mismo tipo en la medida en que los distingue de los demás" (Viveiros, 2003: 225). Según Viveiros para los amerindios el cuerpo no es un mero apelmazamiento de componentes físico-químicos sino "un conjunto de maneras o de modos de ser que constituyen un habitus, un ethos, un ethograma" (Viveiros, 2010: 55). Y, en este sentido, el perspectivismo es somático o, más propiamente, multinaturalista: entre el cuerpo-jaguar, el cuerpo-hombre y el cuerpo-mono, por ejemplo, no sólo hay una diferencia morfológica que no deja de ser importante-, hay una diferencia radical de perspectiva: "los animales ven del mismo modo que nosotros cosas diferentes de las que vemos nosotros, porque sus cuerpos son diferentes de los nuestros" (ibíd.) ${ }^{15}$.

${ }^{14}$ No puede dejar de anotarse la cercanía de este planteamiento con el perspectivismo del Nietzsche de Deleuze. Al analizar la afirmación de la diferencia, Deleuze estudia lo que implica el punto de vista conforme la incomposibilidad de contrarios y su conclusión es casi la misma que apunta Viveiros respecto a los amerindios: "Punto de vista no quiere decir un juicio teórico. El 'procedimiento' es la vida misma. [...] Leibniz [...] sometía los puntos de vista a reglas exclusivas de modo que cada uno sólo se abría a los otros en la medida en que convergían: los puntos de vista sobre la misma ciudad. Con Nietzsche, al contrario, el punto de vista se abre a una divergencia que afirma: es otra ciudad la que corresponde a cada punto de vista [...] La perspectiva -el perspectivismo- de Nietzsche es un arte más profundo que el punto de vista de Leibniz: porque la divergencia deja de ser un principio de exclusión, la disyunción deja de ser un medio de separación, lo incomposible es ahora un medio de comunicación" (Deleuze, 1994: 180). El contexto selvático de la metafísica predatoria permitirá, a diferencia de Nietzsche, la proposición de un campo ontológico particular en el que entre los existentes se cuentan los minerales, los accidentes geográficos, los muertos y los astros, y en el que se requieren procesos de comunicación multinaturales como la transpersonalización chamánica.

${ }^{15}$ Esta noción que asocia la cultura a la corporalidad, está emparentada con varias concepciones de vital importancia dentro de la antropología contemporánea. Viveiros cita a varios de los autores que orientados en esta dirección, renuevan la disciplina (Roy Wagner, Marilyn Strathern, Bruno Latour y Tim Ingold). Siguiéndolo, habría que resaltar a Philippe Descola, quien afirma que "la oposición entre la naturaleza y la cultura no tiene la universalidad que se le adjudica, no sólo porque carece de sentido para quienes no son modernos, sino también por el hecho de que apareció tardíamente en el transcurso del desarrollo del propio pensamiento occidental, donde sus consecuencias se hicieron sentir con singular vigor en la antropología y su manera de considerar su objeto y sus métodos" (2012: 19). Por otro lado, debe destacarse la categoría 'cuerpo cultural', propuesta por López Austin (2008) y descrita por Pinzón y Suárez como una relación homológica entre el cosmos, la organización social, la distribución de los espacios culturales, la actividad económica predominante y el cuerpo (o microcosmos), es decir, que "los órdenes del mundo y de la sociedad son el orden del cuerpo y se rigen por los mismos principios básicos de movimiento" (1992: 46). Lo que estas perspectivas arguyen, es la importancia de repensar las nociones mismas de 'naturaleza' y 'cultura', por lo cual resulta imprescindible a su vez el planteamiento de Marvin Harris (2000), quien critica la consideración de que los hechos mentales (valores, ideas, creencias, etc.) sean de un orden mayor a los fenómenos corporales (como la genética) y al comportamiento aprendido socialmente. De acuerdo con su influencia filosófica, la cual encuentra en Platón, Harris denomina 'postura ideacionalista' (según la 
El multinaturalismo perspectivista amerindio, entonces, puede caracterizarse por los siguientes aspectos: (i) no es un relativismo sino un multinaturalismo, es decir, no expresa una diferencia cultural en el sentido mental sino en cuanto a la corporalidad, diversidad de puntos de vista y construcción de diversos mundos (Viveiros, 2003: 218); (ii) es un manierismo corporal, en tanto trata de "afectos, inclinaciones o capacidades que singularizan cada tipo de cuerpo" (id. 219); y, (iii) es relacionalismo, o sea, algo es una cosa en cuanto lo es para otra: "Alguien es padre sólo porque existen otros de quien él es el padre" (id. 222). Bajo estas consideraciones, Viveiros muestra que en su base, el pensamiento amerindio se distancia del occidental, conduciéndonos a la posibilidad de pensar diferente respecto de nosotros mismos, gracias a la experimentación con el otro. Y sobre la diferencia entre el multinaturalismo perspectivista y el multiculturalismo (o relativismo cultural) concluye lo siguiente:

La teoría indígena del perspectivismo surge de una comparación implícita entre las maneras por las cuales los diversos modos de corporalidad hacen "naturalmente" la experiencia del mundo en cuanto multiplicidad afectiva. Semejante teoría nos parece, así, como una antropología invertida, puesto que nuestra propia etnoantropología procede por la vía de la comparación explícita de las distintas maneras como diferentes tipos de mentalidades se representan "culturalmente" el mundo, planteado éste como el origen unitario de sus diferentes versiones conceptuales (Viveiros, 2010: 74).

En ese sentido, de acuerdo al multinaturalismo perspectivista, no hay que preguntar, por ejemplo, cómo ven el mundo los monos "sino qué mundo se expresa a través de los monos, de qué mundo son ellos el punto de vista" (Viveiros, 2003: 223). Contiene esta idea un sentido profundo de multiverso o de mundos simultáneos de acuerdo a la corporalidad, correspondientes con cada perspectiva. Y más aún, siguiendo a Viveiros, esta concepción supone una suerte de trasfondo o referencial común a todos los seres de la naturaleza, una

traducción que citamos) a esta consideración, y concluye: "cuando definimos la cultura como idea pura y decimos de las ideas que guían el comportamiento social, estamos abogando de hecho por un principio teórico popular cuyo valor científico dista de ser evidente" (2000: 20). La clave de estos discursos es, entonces, mostrar el terreno resbaladizo en que descansan las duplas naturaleza-cultura, mente-cuerpo, razón-instinto y hombre-animal, entre otras similares. 
esencia humana espiritual propia de todos los no-humanos que responde a un momento en el tiempo en que los humanos y los demás seres se encontraban en estado de indiferenciación corporal (existiendo, no obstante, una diferencia potencial o una especificidad en estado virtual).

Con esto se establece otra oposición crucial entre occidentales y amerindios: mientras que occidente establece la desigualdad negando en el animal su humanidad, el amerindio afirma la esencia humana del animal. Para los amerindios, en pocas palabras, "la condición original común a humanos y animales no es la animalidad, sino la humanidad. Los humanos son los que continuaron iguales a sí mismos: los animales son ex humanos, y no los humanos ex animales" (Viveiros, 2003: 198). El animal, entonces, diverge porque es una persona distinta, un cuerpo o punto de vista diferente ${ }^{16}$.

Tal humanidad del animal, en Occidente, no sólo es extraña sino inaceptable. Como ha mostrado Derrida (2008), bien para el creacionismo como para el evolucionismo y la filosofía, a los animales no sólo se les ha negado su humanidad por la falta de una serie de características humanas tan esenciales como graduales que van desde el sentido de desnudez hasta la razón, pasando por la palabra, la técnica, la mirada y el duelo, sino que se les ha considerado propiedad de los hombres: puestos allí para ser dominados (adiestrados, domesticados, domados, sometidos). De este modo, para los occidentales la diferenciación ha sido, más que una especificación o caracterización de lo humano, un ejercicio de jerarquización ${ }^{17}$.

\footnotetext{
16 “Todos los animales y demás componentes del cosmos son intensivamente personas, virtualmente personas, porque cualquiera de ellos puede revelarse como (transformarse en) una persona. No se trata de una simple posibilidad lógica, sino de una potencialidad ontológica. La 'personidad' y la 'perspectividad' -la capacidad de ocupar un punto de vista- son cuestión de grado, de contexto y de posición, antes que propiedades distintivas de tal o cual especie" (Viveiros, 2010: 35, 36-37).

17 Sobre la expresión en singular 'animal', Derrida (2008) enfatizó la pluralidad que se oculta con el fin de establecer la línea por la que podría demarcarse lo que los animales no tienen de humanos. Habría que hablar de animales, en sus diferencias radicales, pero en cambio los occidentales han preferido tratarlos en singular (como una totalidad) para establecer su dominio. El animal, en este sentido, tanto como la naturaleza y el amerindio son expresiones que justifican el ejercicio violento sobre lo Otro. Derrida concibe entonces que el logocentrismo filosófico es inseparable de una posición de dominio.
} 
Por su parte, el multinaturalismo perspectivista establece una diferencia entre 'especies' en la que la verticalidad jerárquica es inexistente, si bien la habilidad predatoria de algunos animales difiere en efectividad de la de otros. En el multinaturalismo perspectivista la diferencia no se marca entre animales y humanos - conceptos, por demás, absurdos o insignificantes- sino entre formas de ver y ser, ethos, personas, cuerpos: "la diferencia entonces debe ser dada por la especificidad de los cuerpos [...] el cuerpo es la sede y el instrumento de la disyunción referencial entre los 'discursos' (los semiogramas) de cada especie” (Viveiros, 2010: 57, 55). Se evidencia así una contradicción insuperable: para Occidente el cuerpo-biológico, atado a las leyes físicas, sigue siendo lo que une, en cierto modo, a hombres y animales -aunque supuestamente haya sido superado por el logos.

Así las cosas, en el pensamiento amerindio los animales no pueden ser el Otro de los hombres, tal como se define la alteridad en Occidente. Por el contrario, tenemos que hablar de una ontología de alteridades conforme a la corporalidad. Viveiros sugiere una situación de alteridad perspectiva: los otros son siempre otras perspectivas, otros cuerpos. Y así, los colectivos de cuerpos similares (es decir, que se ven a sí mismos como iguales o como los mismos), constituirían un nosotros en cuanto comparten una perspectiva que, no obstante, no puede sustancializarse más que siguiendo a la metafísica de la predación, la cual implica, según Viveiros, “un movimiento paradójico de autodeterminación recíproca por el punto de vista del enemigo" (2010: 144).

Esto significa que se habla de sí sólo en cuanto se adquiere o incorpora el punto de vista del otro: "se aprehende como sujeto a partir del momento en que se ve a sí mismo a través de la mirada de su víctima o, más bien, en que pronuncia su singularidad por la voz de su víctima. Perspectivismo" (Viveiros, 2010: 144). La alteridad fundamental tanto como la diferencia irreductible que demuestran la imposibilidad y la necesidad del nosotros, de acuerdo con el campo ontológico de las diferencias, entonces, subyacen a lo esencial de la metafísica predatoria: "la sociedad primitiva como sociedad sin interior, que no llega a ser 'ella misma' más que fuera de sî̀' (Viveiros, 2010: 145-146). 
El multinaturalismo perspectivista trata, pues, de una alteridad subjetivista que no sólo 'reconoce' al Otro como otro, sino que lo concibe desde una comunión: un espíritu común, una misma forma de ver. Y puede afirmarse que la dicotomía entre nosotros y ellos se necesita en función de las implicaciones vitales que representan dos términos, uno respecto del otro, como los mismos y los distintos. Pero al cabo es imposible darle consistencia porque la distinción se estrecha gracias al entrecruzamiento que hace que el nosotros deje de reunir o de significar a los mismos más que atravesados por su diferente (ingerido). El resultado no es la imposibilidad de la diferencia sino su afirmación, ya que la multiplicidad se mantiene, al decir de Viveiros (citando a Deleuze), como "el modo de existencia de la diferencia intensiva pura, esa 'irreductible desigualdad que forma la condición del mundo"” (2010: 102). En concreto, la mismidad de los grupos se diluye en el mundo constituido por la alteridad fundamental: para dar cuenta de los distintos se ha dejado de remitir a los mismos y el Otro del otro resulta ser siempre otro.

Resalta de este modo, junto a la diferencia entre nosotros y ellos, la incomposibilidad entre ellos y nosotros, por la preexistencia de un campo ontológico de alteridad en el que, al decir de Deleuze, "sólo existe la variedad de la multiplicidad, es decir, la diferencia" (2006: 277). Las diferencias demarcan la incompatibilidad al mismo tiempo que consienten el devenir en un campo existencial en que lo diferente es absoluto, por lo que explicitar un nosotros no suscita como base un Mismo ni, mucho menos, una Totalidad, sino más bien, un absolutamente otro. Parafraseando a Deleuze y Guattari (2005: 21 y ss.), el ellos, como conjunto de sujetos que se presentan como 'objeto' ante un 'sujeto', no es más que el Otro tal como se le presenta al 'Yo occidental'; empero, al entenderse el ellos desde el Otro a priori -que no es nadie, ni sujeto ni objeto- debe decirse que existen occidentales y amerindios porque existe (previamente) la alteridad y no a la inversa.

Puntualmente, entonces, resulta imprescindible reconocer la alteridad y la diversidad ontológicas o esenciales que, de acuerdo a la diferencia irreductible, sirven como base a partir de las cuales se engendran las igualdades y desigualdades políticas, tanto como las identificaciones colectivas que constituyen los grupos culturales, esto es, los nosotros (y los ellos) enunciables. No se puede decir únicamente que el sí-mismo se constituye a partir de 
la negación del otro, o que lo haga al verse a sí a través del otro (conforme lo que los otros dicen de él y/o actúan respecto a él); tampoco se trata, como hemos intentado mostrar, que el otro requiera de la mismidad para constituirse como tal, es decir, que la alteridad sea segunda respecto del Mismo (por ejemplo, los 'latinoamericanos' o el 'tercer mundo' en relación con los 'europeos' o el 'primer mundo'); en una palabra, no se llega a ser uno mismo, o un nosotros, sino desde este campo ontológico de la diferencia previo a cualquier clase de mismidad o culturalidad.

Así las cosas, mientras el multiculturalismo ofrece respuestas concretas a problemáticas políticas en sociedades dadas, es decir, donde las diferencias ontológicas se han vuelto ya desigualdades sociales o injusticias que requieren andamiaje jurídico, el multinaturalismo se enlaza fundamentalmente con esta diferencia irreductible conforme la relación predatoria propia del escenario selvático. Es comprensible cómo cada cual sostiene y se sostiene a su vez en una concepción de 'humano' (así como de animal) desde la que se establece cierto tipo de relaciones fácilmente contrastables; pero queda por investigar cuáles podrían ser los aportes y las consecuencias políticas del multinaturalismo en relación con las problemáticas que ha evidenciado la democracia liberal. Se vislumbra la orientación de una política de la diferencia desde la experiencia propia del amerindio, y no una política del reconocimiento de las diferencias según los fundamentos del multiculturalismo.

Por lo pronto, basta decir que la indiferencia es inviable porque no habría manera de explicar la obvia diversidad de formas de vivir tanto entre humanos como entre humanos y animales (necesidad del nosotros); aunque, a la vez, no es posible determinar una unidad sustancial: ésta se rompe en provecho de un desequilibrio constante o, como dice Viveiros citando a Lévi-Strauss, por la asimetría constitutiva de la realidad (2010: 102). Un mundo diverso, por tanto, requiere una mirada más concisa sobre la multiplicidad, de acuerdo con la cual pueda expresarse una ontología de la alteridad lejana del antropomorfismo. En el siguiente apartado avanzaremos en este problema, refiriendo la multiplicidad al nosotros, conforme lo cual se presenta una colectividad inmanente (subyacente y simultánea a la mismidad) compuesta por singularidades (o, en palabras de Deleuze, haecceidades). 


\section{La multiplicidad del nosotros: la colectividad inmanente}

De acuerdo con lo visto, la inevitabilidad de recurrir a un campo ontológico de la diferencia, constituido por la alteridad radical, se sostiene por la consideración de la existencia previa (al Mismo) del Otro. En este campo o plano, coexiste lo diferente como tal, esto es, otros en tanto que otros. El campo ontológico de la diferencia es un plano de diferenciaciones en el que unos otros componen una 'unidad anárquica' ("no la unidad de lo uno, sino una unidad más extraña que sólo se dice de lo múltiple" (Deleuze y Guattari, 1997: 163)), a partir de la cual se da cuenta de una colectividad inmanente expresada como multiplicidad (diferencias infinitas). Conforme este plano, el Mismo no es más que una 'secuela' de la alteridad, una organización de las diferencias o un residuo de las relaciones que se establecen entre los flujos de otredad: corresponde a un plano en el que resulta consistente o trascendente, en el que las desigualdades ontológicas se han vuelto jurídicas, sociales, culturales (diferencias finitas). Por ello, el plano no es moral: el Otro no es alguien en particular, ni hay responsabilidad como sentido elemental de la relación entre diferentes. El campo ontológico de la diferencia está compuesto de unos otros y no de 'el Otro'.

Este campo se presenta así como una alternativa a la sociología institucionalista y, sobre todo, antropomórfica, considerando -en palabras de Gabriel Tarde- una visión sociológica universal o, lo que es lo mismo, el hecho de que "toda cosa es una sociedad" (Tarde, 2006: 55). De acuerdo con esto, en todos los niveles (químico, físico, animal, astral, etc.) subyace una relación social entre (mónadas) diferentes que debido a su diferencia establecen agrupamientos o relaciones de imitación/asimilación, con lo cual se abre una forma de disolución de esos nosotros institucionalizados e institucionalizantes que van desde la conformación de una familia (pasando por todo tipo de agrupaciones normativizadas como las compañías, los sindicatos, los grupos armados y el Estado) hasta su universalización en la figura de la Humanidad. Estos nosotros molares se disipan gracias a la consideración de la colectividad inmanente en la que no se producen cortes o separaciones sin a la vez producirse otras conexiones ${ }^{18}$.

\footnotetext{
${ }^{18}$ La formulación filosófica de Gabriel Tarde sobre el punto de vista sociológico universal, según Eduardo Viana Vargas (en 2006: 16), consiste en una monadología renovada en tanto es "una teoría social que [retiene], de Leibniz, el principio de la continuidad (que fundamenta el cálculo infinitesimal) y el de los
} 
Queda expuesta, pues, la multiplicidad que les subyace a todos los nosotros enunciables, una multiplicidad potenciadora de lo disperso, lo irregular, lo disruptivo en contra de la reproducción, lo igual, lo idéntico: pragmática de la conectividad no identificativa, sino desterritorializada, una colectividad como multiplicidad no totalizable. Ahora bien, para aproximarnos al sentido de esta multiplicidad del nosotros, a continuación analizaremos de la mano de Deleuze y Guattari, tres de sus interrogantes más acuciantes: (i) en qué medida la multiplicidad del 'Yo' remite a la multiplicidad del nosotros; (ii) en qué consiste la diferencia entre lo rizomático y lo segmentario en relación con las asociaciones humanas; y, (iii) cómo se entiende en estas colectividades el problema del lenguaje, de la enunciación de los nosotros.

(i) Varios ejemplos pueden darse respecto de la disolución del sujeto como concepto de lo absoluto -en palabras de Hegel- desde Deleuze y Guattari ${ }^{19}$. Pero quizá, como una suerte de paradigma inevitable, se debe recurrir al inicio de Mil Mesetas (1997: 9), en el que los autores afirman que su escritura 'a dúo' comprende más bien una multiplicidad. En primer

indiscernibles (o de la diferencia inmanente), y que [descarta] los principios de la clausura y de la razón suficiente (en suma, la hipótesis de Dios) en que Leibniz había encerrado a las mónadas". Para Tarde, todo (desde las sociedades humanas hasta las moléculas y los átomos) está compuesto de mónadas, de manera que "por mucho que nos sumerjamos en las profundidades microscópicas, incluso aún ultra-microscópicas de lo infinitamente pequeño, descubrimos siempre allí gérmenes vivientes y organismos completos, en los cuales la observación y la inducción nos llevan a reconocer los caracteres de la animalidad tanto como los de la vegetación, puesto que los dos reinos se confunden in minimis" (2006: 46). Pero su teoría no afirma sólo la existencia de las mónadas como individuos elementales, según dice, "librada a sí misma [...], la mónada nada puede. Ahí reside el hecho fundamental, e inmediatamente sirve para explicar otro, la tendencia de las mónadas a reunirse" (ibíd.: 63). La reunión de las mónadas se da de acuerdo con distintos tipos de relación o apropiación, debido a que la sociedad es "la posesión recíproca, bajo formas extremadamente variadas, de todos por cada uno" (ibíd.: 87); y no debe sorprendernos el hecho de que las mónadas se parezcan, ya que "a decir verdad, no hay de propiamente social más que la imitación de los compatriotas y de los ancestros en el sentido más amplio de la palabra [asociarse quiere decir asimilarse]" (ibíd.: 82). Ahora, decir que las mónadas se parecen, implica su diferencia esencial, lo cual resulta fundamental para el problema que estamos tratando: según Tarde, "en el corazón de las cosas está la diversidad, y no la unidad; [...] La diferencia es alfa y omega del universo; todo comienza por ella [...]; todo acaba por ella [...]" (ibíd.: 79, 7374). Sobre esta diferencia descansa el sentido sociológico universal o la colectividad inmanente.

${ }^{19}$ La disolución del 'sujeto dado' propio de la modernidad filosófica (desde Descartes según muestra y defiende Zizek) ha sido tan potente y ha surcado tantas líneas filosóficas que aún hoy resuenan intentos por restituirle como principio fundamental (de pensamiento tanto como de agencia) en la filosofía moral y política. Los argumentos en contra y a favor son tan dispares que no puede argüirse un solo sentido del problema ni de las posibles soluciones, pero en términos de Deleuze y Guattari el asunto resuena con los procesos de subjetivación de Foucault, de acuerdo con los cuales la subjetividad no está dada sino que es producida (cf. Foucault, 2005; Deleuze, 1987; Guattari, 1996). 
lugar, porque, en sus palabras, "como cada uno de nosotros era varios, en total ya éramos muchos", y el que cada uno sea varios, significa que no se es 'uno mismo' sino, como muchas veces lo afirman, aprehensiones de multiplicidad. Esto es precisamente lo que advierten a propósito de los nombres propios:

El nombre propio no designa un individuo: al contrario, un individuo sólo adquiere su verdadero nombre propio cuando se abre a las multiplicidades que lo atraviesan totalmente, tras el más severo ejercicio de despersonalización. El nombre propio es la aprehensión instantánea de una multiplicidad. El nombre propio es el sujeto de un puro infinitivo entendido como tal en un campo de intensidad (Deleuze y Guattari, 1997: 43$)^{20}$.

Con esta orientación, en la introducción a Mil Mesetas escriben que su escritura hace parte de un agenciamiento colectivo de enunciación en el que se vuelve irreconocible o imperceptible todo lo que los "hace actuar, experimentar, pensar"; de modo que no llegan "al punto de ya no decir yo, sino a ese punto en el que ya no tiene ninguna importancia decirlo o no decirlo” (Deleuze y Guattari, 2004: 15). Cada uno es, en esta medida, no un 'yo' como identidad de sí mismo, sino una singularidad, un nombre propio como 'combinación' de una multiplicidad.

De allí que la expresión "Ya no somos nosotros mismos", describe al sujeto como una absoluta multiplicidad no totalizable, en la que se ha diluido la primera persona del singular tanto como la del plural. En suma, somos una colectividad del tipo muchedumbre, melé, rizoma. La subjetividad, entonces, no es la relación de lo uno con lo uno, de sí mismo consigo mismo, ya que no hay uno mismo; la subjetividad es un efecto de la multiplicidad, de la pluralidad, de la heterogeneidad en el propio cuerpo 'de' cada cual, en 'su' singularidad. Se trata, como dijera Deleuze, de que "todas las identidades sólo son simuladas, producidas como un 'efecto' óptico, por un juego más profundo que es el de la diferencia y de la repetición [de lo diferente]" (2006: 16).

\footnotetext{
${ }^{20}$ Según Deleuze, al abrirse a "las multiplicidades que le atraviesan enteramente, a las intensidades que le recorren [...] uno se ha convertido entonces en un conjunto de singularidades libres, nombres y apellidos, uñas, cosas, animales y pequeños acontecimientos" (1995: 7).
} 
El 'uno mismo' no es una entidad individual, si bien es singular; no está aislada sino conectada con el Afuera; no es una frontera sino -en el lenguaje del Foucault de Deleuzeun doblez del Afuera, un pliegue, una estriación. El cuerpo, en este sentido, es lo más propio -más propio que la mente o las ideas, como decía Nietzsche-; y, también, es lo más propio por ejemplo frente a la muerte - de la que decía Heidegger, es sólo mía. Empero, “¡cada uno pasa por tantos cuerpos en su propio cuerpo!” (Deleuze y Guattari, 1997: 42). Se revela con ello el concepto de una colectividad que en cierto sentido antecede al sujeto y, a la larga, lo produce. Una colectividad que pasa por los afectos tanto como por los enunciados, conforme un movimiento rizomático que se distancia de las segmentaridades.

(ii) Ahora bien, el campo ontológico de la diferencia, la colectividad inmanente, es previa a cualquier organización (grupal o individual) no porque la anteceda -como dicen Deleuze y Guattari- en tiempo, sino porque es como su condición de posibilidad. Es simultáneo a éstas en tanto coexiste con ellas: ninguno se acaba donde o cuando empieza el otro. Por ello, lo importante no es si los colectivos trascendentes (culturales, institucionales, nacionales, etc.) son o no de determinada manera (buenos, malos, imperialistas, democráticos...), o si dejan de ser lo que son (por ejemplo históricamente, o en su contacto con otros), o incluso si conforman a su vez subgrupos o pequeñas identidades (como élites, o bien, facciones subversivas); el problema radica en saber cómo y en función de qué se constituyen y disuelven las organizaciones.

Deleuze y Guattari afirman que el modo sustantivado de lo múltiple, es decir, la multiplicidad, debe dejar de ser atribuida a lo Uno, porque más bien se atribuye ella los individuos o sujetos: deshace los puntos de referencia. Conciben la multiplicidad como un rizoma o un sistema acentrado, es decir, "redes de autómatas finitos en los que la comunicación se produce entre dos vecinos cualesquiera, en los que los tallos o canales no preexisten, en los que los individuos son todos intercambiables, definiéndose únicamente por un estado en un momento determinado, de tal manera que las operaciones locales se coordinan y que el resultado final global se sincroniza independientemente de una instancia central" (Deleuze y Guattari, 1997: 20). Lo contrario, las arborescencias de mando en las que se depende de un General como centro de poder; en el que los comportamientos son 
regulados, ordenados, dirigidos; en el que los flujos son cortados y ya no se pueden conectar dos puntos cualquiera sino que éstos son predefinidos, localizables, referenciados, constituye lo segmentario, lo organizado.

En la segmentarización de los flujos, la multiplicidad es endurecida; se generan procesos de condensación y de ordenación que hacen depender los movimientos de un tronco central, como en los árboles. Aquí, las organizaciones grupales (familiares, políticas, etc.) funcionan como sustanciaciones de la multiplicidad, por lo que se crean identificaciones de colectivo y se separan otras colectividades (nosotros, ellos, los de acá, los de allá, los amigos, los enemigos, los amos, los esclavos, etc.). En la segmentarización de la colectividad inmanente o maquínica -como acontece con la organización orgánica del cuerpo- se constituyen órganos separados que suponen funcionar independientemente. Pero así como los sujetos no son más que un punto de cruce, una combinación de multiplicidad (y los órganos una multiplicidad de flujos y vasos comunicantes), los nosotros que pueden enunciarse, como segmentos del socius o de la colectividad inmanente y rizomática, son una suerte de nodo de esta multiplicidad.

En este sentido, la diferencia que establecen Deleuze y Guattari entre 'sociedades primitivas' y 'sociedades estatales' se basa en el tipo de organización o segmentaridad que cada una tiene. Las primeras, son flexibles, las segundas, son duras. Esta distinción no afecta la inutilidad de la escisión entre 'nosotros' y 'ellos' en términos de la colectividad inmanente, ya que las sociedades organizadas o molares, no dejan de tener flujos moleculares o agenciamientos maquínicos ${ }^{21}$. Estos dos sistemas, molar y molecular, se diferencian por su naturaleza (y no sólo por su talla, escala o dimensión), de manera que siempre se entrecruzan de modos diversos, aunque sus relaciones sean básicamente la de segmentarizar los flujos, por un lado, y la de desterritorializar los segmentos, por el otro.

\footnotetext{
${ }^{21}$ Deleuze y Guattari distinguen, de un lado, dos tipo de multiplicidades, las molares y las moleculares. Para su distinción recurren a los conceptos de masa y de manada según el análisis de Elías Canetti. De otro lado, diferencian dos tipo de multiplicidades, las flexibles y las duras, distinguiendo entre las sociedades modernas y las 'primitivas'. No obstante, reiteran siempre: "Si se distinguen es porque no tienen los mismos términos, ni las mismas relaciones, ni la misma naturaleza, ni el mismo tipo de multiplicidad. Y si son inseparables es porque coexisten, pasan la una a la otra, según figuras diferentes como entre los primitivos o entre nosotros -pero siempre en presuposición la una con la otra-" (Deleuze y Guattari, 1997: 218).
} 
(iii) Finalmente, en cuanto a la enunciación, resulta pertinente decir que son los nosotros repetidos o reiterados los que se conforman o constituyen. Parafraseando a Foucault (1980), es en la repetición donde el nosotros se segmentariza, hace segmentaridad. La invocación de una patria o una tradición, el seguimiento a ciertos signos o imágenes, el constante llamamiento a los otros que están conmigo en un lugar localizable, nombrable, produce estos nosotros que se extraen de la multiplicidad maquínica haciéndose segmentarios. Se crean pues lugares de enunciación y se crean 'sujetos colectivos'. Se hacen modelos y se siguen. Y a su vez, se organizan y delimitan territorios, con sus lugares de entrada y de salida, con sus puntos de control. Por ello, el papel de la enunciación no es menor. Las palabras pesan, lo mismo que movilizan.

No obstante, estos nosotros segmentarizados, como conjuntos molares, no se mantienen fijos eternamente. No hay más fijeza que la de su proceso de cristalización (o repetición del enunciado), ya que son susceptibles de desvanecimiento. Dos cosas son importantes, entonces, para tener en cuenta al respecto. Primero, como hemos dicho atrás, aunque las sociedades sean segmentaridades -aunque se constituyan sobre la colectividad inmanente y rizomática procesos molares de endurecimiento- conservan movimientos moleculares de desterritorialización. Todo proceso de organización (segmentarización o territorialización) supone uno de desterritorialización (desorganización, descodificación). Y, por ello, Deleuze y Guatarri afirman:

Se dice equivocadamente (sobre todo en el marxismo) que una sociedad se define por sus contradicciones. Pero eso sólo es cierto a gran escala. Desde el punto de vista de la micropolítica, una sociedad se define por sus líneas de fuga, que son moleculares. Siempre fluye o huye algo, que escapa a las organizaciones binarias, al aparato de resonancia, a la máquina de sobrecodificación: todo lo que se incluye dentro de lo que se denomina "evolución de las costumbres", los jóvenes, las mujeres, lo locos, etc. $(1997: 220)^{22}$.

\footnotetext{
${ }^{22}$ Un ejemplo paradigmático que gusta mucho a Deleuze y Guattari es Mayo del 68. Pero muestran muchos más, relacionados básicamente con la idea de 'máquina de guerra nómada'. Ahora bien, explicitan que la tarea del historiador consiste en determinar en un 'periodo' los dos movimientos, es decir, distinguir el aspecto molecular y el aspecto molar de un campo social (ver 1997: 225). En este sentido, la denominada
} 
Segundo, los enunciados pertenecen al campo de la colectividad inmanente en el sentido en que sólo son partes de la máquina y no tienen ningún papel privilegiado respecto de ella. Sobre la despersonalización de la que hablábamos más arriba, sobre el abrirse a las multiplicidades que nos atraviesan, descansa el sentido del agenciamiento colectivo de enunciación. En la meseta “¿Uno solo o varios lobos?”, Deleuze y Guattari escriben: “No hay enunciado individual, jamás lo hubo. Todo enunciado es el producto de un agenciamiento maquínico, es decir, de agentes colectivos de enunciación (no entender por 'agentes colectivos' los pueblos o las sociedades)" (1997: 43). Si los 'agentes colectivos' no son pueblos o sociedades, es porque éstos y éstas son estriaciones del campo ontológico: son ya organizaciones del campo de intensidad, son campos trascendentes. Los agentes colectivos son en cambio multiplicidades abiertas o rizomáticas y, por ello, de acuerdo con Deleuze y Guattari,

No hay enunciado individual, sino agenciamientos maquínicos productores de enunciados. [...] Todos estamos incluidos en un agenciamiento de ese tipo, reproducimos el enunciado cuando creemos hablar en nombre propio, o más bien hablamos en nombre propio cuando producimos el enunciado. [...] En efecto, los agenciamientos colectivos de enunciación funcionan directamente en los agenciamientos maquínicos, y no se puede establecer un corte radical entre los regímenes de signos y sus objetos (1997: 42 y 13)

El sentido del agenciamiento colectivo de enunciación consiste en que "el enunciado nunca remite a un sujeto. [...] El enunciado [...] forma parte integral de la máquina, [...] es una parte de la máquina, que va a formar máquina a su vez, para hacer posible el funcionamiento del conjunto, o para modificarlo, o para destruirlo" (Deleuze y Guattari, 2008: 120-118). Como pasaba con Foucault, que escapaba a la función de autor al tiempo que desvanecía al 'sujeto fundador' (como aquel de quien se ‘originan’ enunciados, como

historia no lineal ha mostrado suficientemente tanto ambos aspectos como sus relaciones, de manera que la relación supuestamente causal de la historia es trastocada por la multicausalidad y, más aún, por las relaciones azarosas entre los flujos y entre éstos y sus canalizaciones (cf. De Landa, 2011). Actualmente, se ha hecho bastante divulgación (Chomsky, Castells, y otros) de esta perspectiva de las muchedumbres que se salen y combaten la organización, en relación con movimientos juveniles como los de Medio Oriente que derrocaron 'dictadores', y movimientos como Occupy Wall Street (en Estado Unidos) y el 15M (en España). 
aquel que 'empieza' discursos), el agenciamiento colectivo de enunciación es una suerte de 'voz sin nombre', un inmenso e inconmensurable océano del discurso donde uno se ve envuelto por la palabra "y transportado más allá de todo posible inicio" (Foucault, 1980: 9). Según Deleuze y Guattari, "la enunciación precede al enunciado, no en función de un sujeto que lo produciría, sino en función de un dispositivo [o agenciamiento] que convierte a la enunciación en su primer engranaje, junto con los otros engranajes que van tomando su lugar paralelamente" (2008: 123).

Así, en el maquinismo, aunque se reconozcan dos tipos de multiplicidad (molar y molecular) y dos tipos de segmentaridad (flexible y dura), "no hay dos multiplicidades o dos máquinas, sino un solo y mismo agenciamiento maquínico que produce y distribuye el todo, el conjunto de enunciados que corresponden al "complejo"' (Deleuze y Guattari, 1997: 41). El punto es que la diferencia es necesaria para comprender no sólo de qué manera las formaciones arborescentes cambian, se desvanecen o son alteradas, sino en qué sentido siempre hay multiplicidad y nunca, plena y originalmente, organización e individualidad subjetiva ${ }^{23}$.

Con base en esto, enunciar un nosotros cualquiera en un momento dado, no implica entonces que se elimine la potencia de la colectividad inmanente, de los flujos maquínicos de conexión múltiple. El nosotros enunciado está más bien en un constante juego de estratificación y de disolución, que no se alterna sino que resulta simultáneo. Por ello, aunque enunciarlo resulta inevitable o necesario, a la vez es imposible constituirlo sustancialmente. El nosotros está pues en un constante devenir, como combinación de unos otros que no dejan de conectarse y de separarse en función de otras conexiones. Y, de este modo, siempre hay otros-por-venir como irrupciones del nosotros que se segmentariza al

23 "No basta, pues, con oponer lo centralizado y lo segmentario. Pero tampoco basta con oponer dos segmentaridades, una flexible y primitiva, otra moderna y endurecida. Pues las dos se distinguen perfectamente, pero son inseparables, están enmarañadas la una con la otra, la una en la otra. Las sociedades primitivas tienen núcleos de dureza, de arborificación, que anticipan el Estado en la misma medida en que lo conjuran. Y a la inversa, nuestras sociedades continúan inmersas en un tejido flexible sin el cual los segmentos duros no se desarrollarían. No se puede reservar la segmentaridad flexible para los primitivos. La segmentaridad flexible ni siquiera es la pervivencia del salvaje en nosotros, es una función perfectamente actual e inseparable de la otra. Toda sociedad, pero también todo individuo, están, pues, atravesados por las dos segmentaridades a la vez: una molar y otra molecular" (Deleuze y Guattari, 1997: 217-218). 
enunciarse. Esta es la afirmación de lo Otro en cuanto mundo posible, un nosotros (como pueblo, manada, muchedumbre) abierto a una política cósmica de la diferencia ${ }^{24}$.

De un modo singular, pues, la antropología postestructuralista de Viveiros de Castro, presenta la alternativa amerindia que supone no sólo una cosmopolítica amazónica sino una ontología de la diferencia hermanada con la colectividad inmanente del maquinismo de Deleuze y Guattari. Recuérdese que, según Viveiros, detrás de la metafísica amerindia está "la noción de multiplicidad perspectiva inherente a lo real" (2010: 27), anunciada ya por Levi-Strauss como asimetría primera o disparidad real. Así, de la mano de Levi-Strauss, al intentar "reconstruir el pensamiento de los otros en sus propios términos, de practicar esa 'apertura al Otro"” (2010: 238), Viveiros consigue el experimentar consigo (con Occidente) contra la supuesta inminencia de un nosotros universal occidentalizado.

\section{La condición planetaria: el nosotros de la política cósmica}

¿Es realmente factible, como supuso Tarde, que la diversidad, la heterogeneidad, dada en los estados primigenios de los grupos sociales humanos, a la larga, en el proceso de su desarrollo, tiende a la organización unilateral, a la simetría despótica, a la autoridad homogénea? ¿Acaso la diferencia dentro del nosotros universal trata de una cuestión categorial entre lo global y lo planetario, o entre lo propio y lo local?, ¿trata de la desemejanza de significados, o de una distinción corporal? Si se acepta que la alteridad es esencialmente diferencial (unos otros a priori), ¿podría esperarse que en cierto momento

\footnotetext{
${ }^{24}$ En este sentido, como diría Deleuze, "el problema colectivo consiste entonces en instaurar, encontrar o recuperar el máximo de conexiones. Pues las conexiones (y las disyunciones) son precisamente la física de las relaciones, el cosmos. Hasta la disyunción es física, sólo está como las dos orillas, para permitir el paso de los flujos, o su alternancia. Pero nosotros... nosotros como máximo vivimos en una 'lógica' de las relaciones [...]. La disyunción la convertimos en un 'o, o'. La conexión en una relación de causa efecto, o de principio consecuencia. Del mundo físico de los flujos abstraemos un reflejo, un doble exangüe, compuesto por sujetos, objetos, predicados, relaciones lógicas. Extraemos de este modo el sistema del juicio. No se trata de enfrentar sociedad y naturaleza, artificial y natural. Poco importan los artificios. Pero cada vez que una relación física sea traducida en vinculaciones lógicas, el símbolo en imágenes, el flujo en segmentos, habrá que decir que el mundo ha muerto, y que el alma colectiva a su vez está encerrada en un yo, sea éste el del pueblo o el del déspota. [...] No hay retorno a la naturaleza, sólo hay un problema político del alma colectiva, las conexiones de las que una sociedad es capaz, los flujos que soporta, inventa, deja o hace pasar. Pura y simple sexualidad, sí, si se entiende con ello la física individual y social de las relaciones, por oposición a una lógica asexuada" (Deleuze, 1997: 76-77).
} 
histórico exista un nosotros planetario en tanto que organización total? ¿Supondría esta organización la homogenización cultural?, ¿se impondría un solo modelo de vivir a los diferentes?, ¿serían las diferencias administradas en función de su reconocimiento aunque asimiladas al Uno ${ }^{25}$

Como es sabido, el temor a este posible futuro radica en que tal nosotros puede ser una condición necesaria de un gobierno con pretensiones globales, en el cual se sitúan ciudadanos del mundo bajo un mismo régimen de acción legal y de producción económica. Este sería un sistema que, aun derivado de la hospitalidad universal kantiana, si fuera el caso, realmente no tendría en cuenta el efecto de interpelación que contiene el contacto real entre formas de vivir distintas, debido a que las asimilaría en el esquema del régimen político - por supuesto liberal. Esta consideración se fundamenta en el hecho inapelable que, si bien la esfera o el globo ha sido una figura recurrente del pensamiento conquistador en toda la historia de occidente, tal como plantea Sloterdijk (2007), según Todorov (1998) con la llegada de Colón al continente americano se inicia una nueva época de globalidad incomparable respecto tanto a la idea de la conjunción universal del globo como a la política mundial -o, si se quiere, al nuevo imperialismo capitalista ${ }^{26}$.

De acuerdo con esta perspectiva, a partir de finales del siglo XV la topografía del planeta se encuentra completa, ya no hay más que agregar, la esfera se cierra. Inicia así, en la plenitud que tiene para nuestra actualidad, la condición de globalización. Y, en tal condición, las historias se entrecruzan cada vez más con mayores implicaciones; una a una, las comunidades aisladas harán parte del globo, se incluirán en él. De este modo, la conquista

\footnotetext{
${ }^{25}$ Aunque la diferencia y la multiplicidad se evidencian por doquier, también se ve en todos los reinos una tendencia a la simetría, a las leyes (naturales), a la similitud, a la repetición de los fenómenos, surgida, según Tarde, "del triunfo de ciertas mónadas que han deseado esas leyes, impuesto esos tipos, puesto su yugo, y pasado su falsificación sobre un pueblo de mónadas uniformizadas y esclavas, pero todas nacidas libres y originales, todas ávidas, como sus conquistadores, de la dominación y asimilación universales" (2006: 53). De este modo, afirma Tarde, "observamos que en nuestro mundo social, todo lo que es obra, no del concurso de intenciones mezcladas que se traban, sino de un plan personal ejecutado sin restricción, es simétrico y regular" (2006: 60).

26 "Cierto es que la historia del globo está hecha de conquistas y de derrotas, de colonizaciones y de descubrimientos de los otros; pero [...] el descubrimiento de América es lo que anuncia y funda nuestra identidad presente; aun si toda fecha que permite separar dos épocas es arbitraria, no hay ninguna que convenga más para marcar el comienzo de la era moderna que el año de 1492, en que Colón atraviesa el océano Atlántico" (Todorov, 1998: 15. Cursivas mías).
} 
de América demarca, según se ha dicho, el advenimiento de la Humanidad: de un lado, por el 'reconocimiento' que los europeos harán de los nativos como seres humanos o poseedores de alma; y de otro, por la 'asimilación' que se hará de ellos hasta instaurar un destino común (siendo América utilizada, por supuesto, como zona de abastecimiento mundial). La Humanidad y el Globo se convierten, entonces, en una suerte de nosotros incondicional a través del cual se administran las diferencias. Y, en este sentido, el descubrimiento del Otro desde el Mismo proporciona el afán por afianzar la mismidad (véase Levi-Strauss, 1993).

En este orden de ideas, la globalización o mundialización constituye un nosotros especialmente problemático. Particularmente, para Viveiros, ésta puede formularse como "la propagación de la peste neoliberal y la consolidación tecnopolítica de las sociedades de control (el Mercado es el Estado, el Estado es el Mercado: no es cuestión de elegir entre los dos)" (2010: 86). Y, si por globalización y multiculturalidad se entiende el exterminio del otro (por vía militar, jurídica o mediática), resulta entonces necesario rehacer el sentido de la condición de estar en un mismo 'globo'. En esta dirección, Moacir Gadotti (2002) ha trazado a la planetariedad como alternativa a la globalización, instaurando ésta el hecho de sentir-se, pensar-se y actuar como 'seres vivos' que conviven con otros en el planeta Tierra. Guardando las diferencias, pero sin forzar los términos, diríase con Viveiros que la planetariedad, más que una existencia material compartida, es la condición vital de los cuerpos o de las especies que comparten un "espacio abstracto de divergencia entre ellas en cuanto puntos de vista" (Viveiros, 2010: 77). Y así entendidos, la planetariedad y el multinaturalismo perspectivista, sirven para hacer de la metafísica predatoria amerindia, el principio de una política alternativa al multiculturalismo ${ }^{27}$.

Esta otra política, resulta ser una suerte de pragmática no global sino cósmica. En primer lugar, la inversión de la relación hombre-naturaleza, o bien cultura-naturaleza, que reorienta las implicaciones de la diversidad cultural conforme la introducción del cuerpo-agente,

\footnotetext{
${ }^{27}$ Para un análisis más detallado del posible diferendo entre multiculturalismo y perspectivismo (que toma en consideración no sólo diversas formas de pensar el primero a partir de las prácticas políticas de los países europeos y del Estado-nación sino, además, un horizonte de sentido amerindio del perspectivismo en línea con Viveiros de Castro) y del papel del mismo en América Latina, véase Chaparro Amaya (2004).
} 
evidencia que un cambio de significaciones o representaciones es insuficiente cuando se requiere un cambio de formas de vivir. Por su parte, el cuerpo como ethos presenta un esquema en el que éstas, aunque no se independizan del pensamiento, adquieren un valor práctico fundamental. En segunda medida, el perspectivismo que ya no asume la localización de un sujeto en una cultura u otra, sino la subjetivación en relación con un punto de vista, abre posibilidades a la experimentación de otros mundos posibles: exploración del Otro como experimentación con lo propio. Y, finalmente, en concordancia con lo anterior, la apertura al multiverso implica la 'creación' en tanto que realización de lo Otro o actualización de virtualidades, lo cual podría exponerse a su vez como el efectuar lo por-venir en la medida en que no se trata ni de un modelo de mundo universal por petrificar, ni de una ilusión (siempre lejana) por alcanzar ${ }^{28}$.

Se trata de una política de la diferencia con base en el hecho de que "el multinaturalismo amazónico no afirma tanto una variedad de naturalezas como la naturalidad de la variación, la variedad como naturaleza" (Viveiros, 2010: 58). La cuestión es muy simple,

[mientras que] el relativismo cultural, o el multiculturalismo, supone una diversidad de representaciones subjetivas y parciales, incidentes sobre una naturaleza externa, una y total, indiferente a la representación, [1]os amerindios proponen lo contrario. [...] El multinaturalismo no supone una Cosa-en-Sí parcialmente aprehendida por las categorías del entendimiento propias de cada especie [...]. Lo que existe en la multinaturaleza no son entidades autoidénticas diferentemente percibidas, sino multiplicidades inmediatamente relacionales (Viveiros, 2010: 54, 56).

Es muy probable que la interrogación por la convivencia entre diversas culturas no encuentre salida mientras siga atada a las consideraciones mentales o ideacionales de la

\footnotetext{
${ }^{28}$ Recuérdese que la actualización o encarnación de las ideas entendidas como 'virtualidades', según Deleuze, sucede por diferenciación: "la Idea sólo se actualiza en la medida en que sus relaciones diferenciales se encarnan en especies o cualidades separadas, y en la medida en que las singularidades concomitantes se encarnan en una extensión que corresponde a aquella cualidad. [...] Para ella, actualizarse es diferenciarse" (2005: 134). De este modo, "lo virtual no se opone a lo real. Lo que se opone a lo real es lo posible. Lo virtual se opone a lo actual y, en este sentido, posee una realidad plena" (Deleuze, 2005: 135). Ahora, "la diferenciación o la actualización son siempre creadoras con respecto a lo que actualizan [...]. La diferencia entre lo actual y lo virtual no es la de lo Mismo en cuanto puesto una vez en la representación y otra fuera de ella, sino la de lo Otro en cuanto aparece una vez en la Idea y otra vez, de modo completamente diferente, en el proceso de actualización de la idea" (Deleuze, 2005: 135-136).
} 
cultura y, por ende, a las del sujeto y la intersubjetividad. Como hemos dicho, la multiplicidad del nosotros no se afirma por la cantidad de grupos a los que un sujeto puede pertenecer en la interacción con otros. El ser/estar-en-común no supone nunca un sujeto dado que cambia según el contexto, sino procesos de subjetivación incesantes que, en palabras de Viveiros, son como la adquisición de un punto de vista u otro. La multiplicidad de la identidad, en este sentido, cuando es referida a capas o planos como camisetas que se pone un mismo sujeto dependiendo de con quién esté o en qué lugar interactúe, o como cajas dentro de cajas, resulta demasiado pobre.

Así, al decir de Viveiros de Castro, "si el multiculturalismo occidental es el relativismo como política pública, el perspectivismo chamánico amerindio es el multinaturalismo como política cósmica" (2003: 200). La política cósmica es la praxis de diferenciación constante o de alteridad radical. Y, teniendo en cuenta la multiplicidad del nosotros en la que el mundo no es más que una composición rizomática de diferenciales -individualidades impersonales pero potencialmente subjetivas-, el nosotros político de la planetariedad, ha de asumir ya no la (sagrada) vida del hombre cultural como representación de un mismo mundo dado (y, por tanto, la necesidad de una negociación de valores culturales), sino la transpersonalización como 'técnica' general de conocimiento y de agencia en medio de la multiplicidad de perspectivas, tal como lo es para el chamán según indica Viveiros ${ }^{29}$.

A partir del planteamiento de Viveiros sobre los amerindios, entonces, los colectivos (no sólo humanos) pueden ser vistos como multiplicidades personales (los Otros en tanto que personas), y no como asociaciones contractuales. A su vez, la constitución de nosotros (como la manada o la pandilla) puede ser considerada como la 'consecución' de puntos de

\footnotetext{
29 Por transpersonalización, distante de la epistemología occidental, debemos comprender el hecho de "tomar el punto de vista de aquellos que deben ser conocidos; de aquello, o mejor, de aquél; pues el conocimiento chamánico se dirige a un 'algo' que es en verdad un 'alguien', otro sujeto o agente" (Viveiros, 2003: 201). Siguiendo a Viveiros el modo de conocimiento chamánico "se encuentra por varias razones en el polo opuesto de la epistemología objetivista favorecida por la modernidad occidental. En esta última, la categoría del objeto nos proporciona el telos: conocer es objetivar [...]. Conocer, así, es des-subjetivizar, explicitar la parte del sujeto presente en el objeto, de modo que se pueda reducir a un mínimo ideal. Los sujetos, igual que los objetos, son vistos como resultantes de procesos de objetivación; el sujeto se constituye o reconoce a sí mismo en los objetos que produce y se conoce objetivamente cuando consigue verse 'desde fuera', como un 'eso'. [...] lo que no fue objetivado permanece irreal y abstracto. La forma del Otro es la cosa. [Al contrario, en el chamanismo amerindio] la forma del Otro es la persona" (2003: 200201). Conocer es personificar.
} 
vista comunes. El ser/estar-en-común, en este sentido, no es otra cosa que intercambiar un punto de vista o una personalidad, esto es, el realizar "la circulación infinita de perspectivas; intercambio de intercambios, metamorfosis de metamorfosis, punto de vista sobre punto de vista, es decir: devenir" (Viveiros, 2010: 242). Así, la máquina planetaria capitalista es enfrentada con la idea de que otro mundo es posible, o de que el Otro es un mundo posible respecto del multiverso real en que vivimos.

La tesis de este ensayo, pues, es muy simple: enunciar un nosotros es tan necesario como imposible es su constitución sustancial. Lo hemos mostrado conforme tres argumentos: primero, en la construcción de las teorías sociales de la antropología participan activamente tanto el antropólogo occidental como la comunidad estudiada (a pesar de que el antropólogo no lo reconozca) en una suerte de hibridación disciplinar. Segundo, aunque la diferenciación entre occidentales y amerindios y entre animales y humanos permita denotar oposiciones, lo que los humanos tienen de animales (y viceversa) y lo que los occidentales tienen de amerindios (y viceversa), en la medida en que se estudian sus particularidades, devela que las diferencias no se construyen por la negación del otro (en tanto que un noYo) sino por su afirmación en un campo ontológico de alteridad en el cual lo diferente posibilita el devenir, el entrecruzamiento de perspectivas. Finalmente, sobre este campo se ha mostrado que el Yo o el Mismo, tanto colectivo como individual, se diluye en función de la multiplicidad que le subyace: no sólo cada 'uno' es 'muchos', sino que a la solidez de 'la mayoría' siempre 'una minoría' resquebraja y hace flujo; el flujo y la multiplicidad son primordiales, constituyen el maquinismo que es pura alteridad diferencial y, por ello, la enunciación no es más que parte de la máquina.

La necesidad del 'nosotros', entonces, se sostiene únicamente para resaltar una diferencia actual y una distancia o partición respecto del otro presente; pero constituidas tales distancias, el nosotros a su vez termina diferenciándose y distanciándose de sí mismo (o de la mismidad que confiaba mantener) debido a la desterritorialización de sí en la relación con el otro, en el por-venir abierto por lo Otro. De este modo, la única forma de hacer prevalecer el nosotros no es a través de la exclusión de un ellos; sino por un acto radical de diferenciación primigenia. Siguiendo a Deleuze, si generalmente dos cosas se afirman 
simultáneamente sólo al negárseles su diferencia, por la alteridad radical y la diferencia irreductible, dos determinaciones - como el nosotros y el ellos, o como el nosotros actual y el nosotros por-venir- "no son objetos de afirmación simultánea sino en la medida en que su diferencia es también afirmada, es también afirmativa" (1994: 179).

No se trata en absoluto de una identidad de los contrarios, todavía inseparable en tanto que tal de un movimiento de lo negativo y de la exclusión. Se trata de una distancia positiva de los diferentes: no ya identificar dos contrarios a lo mismo, sino afirmar su distancia como aquello que los remite uno a otro en tanto que “diferentes” (Deleuze, 1994: 179).

Con base en este análisis, decir nosotros no refiere necesariamente a un conjunto, ni a una identidad colectiva, ni a una oposición entre colectividades, aunque se enuncie en situaciones a las que se les puede adjudicar alguna de estas tres condiciones (nosotros los humanos, nosotros los negros, nosotros los de acá). El nosotros responde más bien a una relación o, mejor, a una implicación recíproca asimétrica entre existentes, en un multiverso general de alteridad fundamental repleto de subjetividades potenciales (como puntos de vista o mundos posibles). Por ello, su insustancialidad comporta siempre una posibilidad: el posible ser-otro distinto del que se-es. Encontramos, así, convergiendo en Deleuze y Guattari, una muchedumbre que se presenta como conexiones heterogéneas en un plano de colectividad insustancial e informe, que no agrupa o unifica sino mantiene en conexión. Una relación o flujo constante entre singularidades asubjetivas y preindividuales que constituyen -conforme dos tipos de procesos articulatorios: repartición y consolidación, o sedimentación y plegamiento-segmentarizaciones en las que los grupos y los individuos se afirman mientras se separan. Se trata de una colectividad que subyace como 'condición de posibilidad', coexistente con cualquier mismidad (individual o grupal) y en la que se despliega una micropolítica corporal y/o deseante (Foucault, 2005, 2006; Deleuze y Guattari, 1995, 1997), logrando que las condiciones de colectividad y exclusividad del enunciado nosotros (en contra del 'ellos') se disuelvan en provecho de una diferencia esencial y una alteridad radical: el Otro de los otros es siempre otro. 


\section{Bibliografía}

Bartra, Roger. 2013. Territorios del terror y la otredad. México: Fondo de Cultura Económica.

Chaparro Amaya, Adolfo. 2004. "El diferendo entre multiculturalismo y perspectivismo".

En Estudios de Filosofía No. 30. Colombia: Universidad de Antioquia.

De Landa, Manuel. 2011. Mil años de historia no lineal. México: Gedisa Editorial.

Deleuze, Gilles. 1987. Foucault. España: Ediciones Paidos Ibérica.

Deleuze, Gilles. 1995. Conversaciones. España: Pre-textos.

Deleuze, Gilles. 1994. Lógica del Sentido. España: Editorial Planeta.

Deleuze, Gilles. 2005. La isla desierta y otros textos. Textos y entrevistas (1953-1974). España: Pre-Textos.

Deleuze, Gilles. 2006. Diferencia y repetición. Buenos Aires: Amorrortu Editores.

Deleuze, Gilles y Guattari, Félix. 1997. Mil Mesetas. Capitalismo y esquizofrenia. España: Editorial Pre-Textos.

Deleuze, Gilles y Guattari, Félix. 2005. Qué es la filosofía. Barcelona: Editorial Anagrama.

Deleuze, Gilles y Parnet, Claire. 2004. Diálogos. España: Pre.Textos.

Descartes, Renato. 1974. Discurso del Método. Argentina: Aguilar Ediciones.

Descola, Phillippe. 2012. Más allá de Naturaleza y Cultura. Buenos Aires: Amorrortu.

Derrida, Jacques. 2008. El animal que luego estoy si(gui)endo. Madrid: Editorial Trotta.

Foucault M. 1980. El Orden del Discurso. Barcelona: Tusquets editores

Foucault M. 2005. El sujeto y el poder. Pensamiento y Experimentación. Bogotá: Ediciones Carpe Diem y Tejer.

Foucault M. 2006. Vigilar y Castigar. Colombia: Círculo de Lectores.

Gadotti, Moacir. 2002. Pedagogía de la Tierra. México: Siglo XXI Editores.

Gómez de Silva, Guido. 2006. Breve Diccionario Etimológico de la Lengua Española. México: Fondo de Cultura Económica.

Grosso Lorenzo, José Luis. 2006. "Un Dios, una raza, una lengua'. Conocimiento, sujeción y diferencias en nuestros contextos interculturales postcoloniales. Revista Colombiana de Educación No. 50. Bogotá: Universidad Pedagógica Nacional.

Guattari, Félix. 1996. Caosmosis. Argentina: Ediciones Manantial.

Kymlicka, Will. 2009. Las odiseas multiculturales. Barcelona: Ediciones Paidós Ibérica.

Lazzarato, Maurizio. 2007. La filosofía de la diferencia y el pensamiento menor. Bogotá: Universidad Central, Instituto de Estudios Sociales Contemporáneos.

Levi-Strauss, Claude. 1993. Raza y Cultura. Madrid: Ediciones Cátedra.

López Austin, Alfredo. 2008. Cuerpo humano e ideología. Las concepciones de los antiguos nahuas. México: UNAM, Instituto de Investigaciones Antropológicas.

Harris, Marvin. 2000. Teorías sobre la cultura en la era posmoderna. Barcelona: Editorial Crítica.

Hegel. G.W.F. 1993. Fenomenología del espíritu. Colombia: Fondo de Cultura Económica.

Narváez M. Ancízar. 2005. Multiculturalismo y mercado: las puntas de la madeja. Revista Colombiana de Educación No. 48. Bogotá: Universidad Pedagógica Nacional.

Pinzón C. y Suárez R. 1992. Las Mujeres Lechuza. Historia, cuerpo y brujería en Boyacá. Colombia: Instituto Colombiano de Antropología e Historia y CEREC.

Sloterdijk, Peter. 2007. En el mundo interior del capital: para una teoría filosófica de la globalización. Madrid: Ediciones Siruela.

Tarde, Gabriel. 2006. Monadología y sociología. Buenos Aires: Cactus. 
Taylor, Charles. 1993. El multiculturalismo y "La política del reconocimiento". México: Fondo de Cultura Económica.

Todorov, Tzvetan. 1998. La conquista de América. El problema del otro. México: Siglo XXI Editores.

Villa, Wilmer y Grueso, Arturo (Ed.). 2008. Diversidad, interculturalidad y construcción de ciudadanía. Bogotá: Universidad Pedagógica Nacional, Secretaría de Gobierno de Bogotá, Secretaría de Cultura, Recreación y Deporte de Bogotá.

Viveiros de Castro, Eduardo. 2010. Metafísicas caníbales. Líneas de antropología postestructural. Buenos Aires: Katz Editores.

Viveiros de Castro, Eduardo (2003). "Perspectivismo y Multinaturalismo en la América Indígena", en: Adolfo Chaparro y Christian Schumacher (editores) Racionalidad y Discurso Mítico. Bogotá: Centro Editorial Universidad del Rosario, ICANH, pp. 191-243.

Winch, Peter. 1994. Comprender una sociedad primitiva. España: Ediciones Paidós Ibérica.

Zemelman, Hugo. 2011. Conocimiento y sujetos sociales: contribución al estudio del presente. Bolivia: Instituto Internacional de Integración del Convenio Andrés Bello.

Zemelman, Hugo. 2006. "Pensar la Sociedad y a los sujetos sociales". Revista Colombiana de Educación No. 50. Bogotá: Universidad Pedagógica Nacional. 